\title{
Electroencephalographic Abnormalities in Clozapine-Treated Patients: A Cross-Sectional Study
}

\author{
Nishant Goyal' ${ }^{1}$, Samir Kumar Praharaj ${ }^{2}$, Pushpal Desarkar ${ }^{3}$ and Haque Nizamie ${ }^{4}$ \\ ${ }^{1}$ Senior Resident, Centre for Cognitive Neurosciences, Central Institute of Psychiatry, Kanke, Ranchi, Jharkhand, India \\ ${ }^{2}$ Department of Psychiatry, Kasturba Medical College, Manipal, Karnataka, India \\ ${ }^{3}$ Consultant Child and Adolescent Psychiatrist, Oxfordshire and Buckinghamshire Mental Health NHS Foundation Trust, \\ Boundary Brook House (Park Hospital), Churchill Drive, Headington, Oxford, OX3 7LQ, UK \\ ${ }^{4}$ Professor of Psychiatry, In Charge Center for Cognitive Neurosciences, Central Institute of Psychiatry, Kanke, Ranchi, Jharkhand, India
}

The objective of our study was to examine the electroencephalogram (EEG) abnormalities associated with clozapine treatment. It was a cross-sectional study on 87 psychiatric patients on clozapine treatment. 32 channel digital EEG was recorded and analysed visually for abnormalities. EEG abnormalities were observed in $63.2 \%$ of patients. Both slowing and epileptiform activities were noted in $41.4 \%$ of patients. The EEG abnormalities were not associated with dose or duration of clozapine exposure. Psychiatry Investig 2011;8:372-376

Key Words Clozapine, EEG abnormalities, Seizures.

\section{INTRODUCTION}

Clozapine is a dibenzodiazepine derivative which has receptor blocking activity at dopamine $\mathrm{D}_{1}$ and $\mathrm{D}_{4}$ as well as serotonin $5-\mathrm{HT}_{1 \mathrm{~A}}$ and $5-\mathrm{HT}_{2}$ receptors. ${ }^{1,2}$ It is an atypical antipsychotic that has been shown to be effective in treating patients with refractory schizophrenia. ${ }^{3}$ Clozapine also is less likely to cause extrapyramidal adverse effects including tardive dyskinesia than other antipsychotics. ${ }^{4}$ However, it has propensity to cause severe adverse effects such as agranulocytosis (1-2\%) ${ }^{5}$ and an unusually high incidence of seizures. ${ }^{6,7}$

Recent estimates of incidence of clozapine-induced seizures vary from $1.3 \%{ }^{8}$ to $2.8 \% .{ }^{9}$ Even higher occurrence rates of seizures have been reported in more selected populations such as state hospital patients ${ }^{10}$ or brain injured patients. ${ }^{11}$ There is evidence that the risk for seizures is dose-related, ${ }^{7,12}$ although seizures can occur in all dose ranges ${ }^{10}$ and even at very low doses. ${ }^{13}$

Electroencephalogram (EEG) abnormalities have been reported to occur frequently in several retrospective studies of pa-

Received: January 29, 2011 Revised: July 21, 2011

Accepted: July 23, 2011 Available online: December 8, 2011

$\triangle$ Correspondence: Samir Kumar Praharaj, MD, DPM

Assistant Professor, Department of Psychiatry, Kasturba Medical College, Manipal, Karnataka, India

Tel: +91-8971026304, Fax: +91-820-2571930

E-mail: samirpsyche@yahoo.co.in; psynishant@gmail.com

(1) This is an Open Access article distributed under the terms of the Creative Commons Attribution Non-Commercial License (http://creativecommons.org/licenses/bync/3.0) which permits unrestricted non-commercial use, distribution, and reproduction in any medium, provided the original work is properly cited. tients treated with clozapine; ${ }^{14-18}$ it ranges from $53 \%{ }^{17}$ and $59 \%{ }^{15}$ to $74 \% .{ }^{18}$ Generalized slowing has been reported as the most prominent finding, followed by epileptiform activities such as spike-waves and sharp activities. ${ }^{15,17-19}$ Several but not all studies found EEG changes associated with clozapine to be doserelated. ${ }^{17,18,20}$ Furthermore, studies have shown that the plasma levels of clozapine predict pathological EEG changes as well as the occurrence of seizures. ${ }^{21,22}$ Some of these seemingly contradictory observations might be explained by clozapine's wide range of plasma level for a given dose. ${ }^{21}$ Volavka et al. ${ }^{23}$ reported that clozapine differed from the other antipsychotics by producing more EEG slowing and epileptiform activity. The aim of our study was to explore and characterize the EEG abnormalities associated with clozapine treatment.

\section{METHODS}

This was a cross-sectional study conducted at Center for Cognitive Neurosciences, Central Institute of Psychiatry, Ranchi, India. Sample consisted of 87 patients on clozapine treatment for various psychiatric disorders. All the patients were receiving clozapine for at least two weeks. Patients with history of seizures in the recent past were excluded from the study. Digital EEG was recorded in awake state with eyes closed using $21 \mathrm{Ag}$ $\mathrm{AgCl}$ electrodes (32 channels) placed according to the international 10-20 system using Neurofax EEG-9000 (Nihon Kohden, Japan) amplifiers (sampling rate $512 \mathrm{~Hz}$, TC $0.1 \mathrm{Sec}$, 
HFF $70 \mathrm{~Hz}$ ) with linked ear electrodes as reference. Three minutes of hyperventilation as well as photic stimulation in different frequencies were also obtained. Visual analysis of the EEG was carried out by the author NG, having experience in EEG interpretation after appropriate training, to characterize background activity as well as to identify slow waves and epileptiform activity (spike-waves, polyspike-waves or sharp waves) and their localization. EEG abnormalities were categorized on the basis of duration of abnormalities in 95 to 100 epochs each of 10 seconds duration in real time that were characterized as 'mild' (<25\% of epochs), 'moderate' ( $25-50 \%$ of epochs), and 'severe' ( $>50 \%$ of epochs or polyspikes).

The data obtained were analyzed with Statistical Package for Social Sciences-version 10.0 for Windows ${ }^{\circledR}$ (SPSS Inc., Chicago, IL, USA). Continuous variables were analyzed using independent sample ' $\mathrm{t}$ ' test and categorical data was analyzed using Pearson's chi-square test. Level of significance was set at $\mathrm{p}<$ 0.05 (two-tailed). Logistic regression analysis (backward conditional method) was carried out with presence or absence of EEG abnormality as outcome variable. Age, gender, clozapine dose, duration on clozapine and medications were entered as predictor variables.

\section{RESULTS}

Sample consisted of 76 (87.4\%) males and 11 (12.6\%) females. Mean age of the sample was 32.76 (SD 11.10) years and mean duration of illness was 92.39 (SD 64.79) months. Entire sample was right handed. Daily clozapine doses varied from 25 to 800 (mean 293.10, SD 172.55) mg/day and mean duration on clozapine was 15.07 (SD 8.98) weeks. Fifty-six (64.4\%) patients were on clozapine alone, whereas $19(21.8 \%)$ received valproate, 7 (8\%) other antipsychotics and 5 (5.7\%) antidepressants along with clozapine. Sixty-three (72.4\%) had schizophrenia, 9 (10.3\%) had mood disorders and 6 (6.9\%) had schizoaffective disorder. Five (5.7\%) patients had past history of epilepsy during childhood and three (3.4\%) patients had head injury or central nervous system infection. EEG abnormalities associated with clozapine are summarized in Table 1. There was no difference in clozapine dose between patients with or without EEG abnormalities $(t=0.96, \mathrm{p}=0.342)$. Abnormal EEG was found in 34 (66.7\%) patients receiving clozapine more than $300 \mathrm{mg} /$ day, whereas it was seen in 21 (58.3\%) patients receiving clozapine less than $300 \mathrm{mg} /$ day. Among those receiving clozapine $100 \mathrm{mg}$ or less per day $(\mathrm{n}=21)$, EEG was abnormal in 13 (61.9\%) patients, whereas in those receiving clozapine $50 \mathrm{mg}$ or less per day $(\mathrm{n}=12)$ and $25 \mathrm{mg}$ or less per day $(\mathrm{n}=7)$, abnormal EEG was found in $6(50 \%)$ and $4(57.1 \%)$ patients, respectively. Abnormal EEG was found in 38 (67.9\%), $11(57.9 \%), 3(42.9 \%)$ and $3(60 \%)$ patients, among those re-
Table 1. Frequency of EEG abnormalities associated with clozapine $(\mathrm{N}=87)$

\begin{tabular}{|c|c|c|}
\hline EEG abnormalities & $\mathrm{N}$ & $\%$ \\
\hline Abnormal EEG & 55 & 63.2 \\
\hline Background asymmetry & 1 & 1.1 \\
\hline Background asynchrony & 0 & 0 \\
\hline Poorly regulated background & 1 & 1.1 \\
\hline Slow waves present & 36 & 41.4 \\
\hline \multicolumn{3}{|l|}{ Slow wave details } \\
\hline Focal & 8 & 9.2 \\
\hline Regional & 7 & 8.0 \\
\hline Lateralized & 1 & 1.1 \\
\hline Generalized & 17 & 19.5 \\
\hline Combination & 3 & 34 \\
\hline \multicolumn{3}{|l|}{ Slow wave type } \\
\hline Theta & 18 & 20.7 \\
\hline Delta & 8 & 9.2 \\
\hline Both & 9 & 10.3 \\
\hline Epileptiform activity & 36 & 41.4 \\
\hline \multicolumn{3}{|l|}{ Epileptiform activity details } \\
\hline Focal & 6 & 6.9 \\
\hline Regional & 8 & 9.2 \\
\hline Lateralized & 1 & 1.1 \\
\hline Generalized & 13 & 14.9 \\
\hline Combination & 7 & 8.0 \\
\hline Abnormality with activation procedures & 4 & 4.6 \\
\hline \multicolumn{3}{|l|}{ Severity of abnormality } \\
\hline Mild & 5 & 5.7 \\
\hline Moderate & 26 & 29.9 \\
\hline Severe & 24 & 27.6 \\
\hline
\end{tabular}

EEG: electroencephalogram

ceiving clozapine only, clozapine with sodium valproate, clozapine with antipsychotics and clozapine with antidepressants, respectively.

There was no difference in the frequency of EEG abnormalities $\left(\chi^{2}=1.45, \mathrm{p}=0.228\right)$, presence of slow waves $\left(\chi^{2}=0.14, \mathrm{p}=\right.$ $0.707)$ or epileptiform activities $\left(\chi^{2}=0.69, p=0.406\right)$ among patients receiving clozapine alone or clozapine with other drugs. There was no significant difference in age, sex, duration of illness and duration on clozapine treatment between the patients with or without EEG abnormalities (Table 2). Thirtyeight (69.1\%) patients out of 63 patients with schizophrenia had abnormal EEG, although it was not significantly higher than patients with other diagnoses $\left(\chi^{2}=0.83, p=0.36\right)$. None of the patients developed clinical seizures. Logistic regression analysis did not identify any significant predictors of EEG abnormalities (Table 3). 
Table 2. Comparison of clinical characteristics between those with and without EEG abnormalities associated with clozapine

\begin{tabular}{|c|c|c|c|c|c|}
\hline & & $\begin{array}{l}\text { Without EEG abnormalities } \\
\qquad(\mathrm{N}=32)\end{array}$ & $\begin{array}{l}\text { With EEG abnormalities } \\
\qquad(\mathrm{N}=55)\end{array}$ & $t / x^{2}$ & $\mathrm{p}$ \\
\hline \multicolumn{2}{|l|}{ Age, Mean (SD) } & $35.16(9.87)$ & $31.37(11.62)$ & 1.55 & 0.13 \\
\hline \multicolumn{2}{|c|}{ Duration of illness (mths), Mean (SD) } & $96.59(59.96)$ & $89.94(67.87)$ & 0.46 & 0.65 \\
\hline \multicolumn{2}{|c|}{ Duration on clozapine (wks), Mean (SD) } & $14.31(9.20)$ & $15.52(8.91)$ & -0.60 & 0.55 \\
\hline \multicolumn{2}{|l|}{ Clozapine dose, Mean (SD) } & $269.92(170.06)$ & $306.59(174.10)$ & -0.96 & 0.34 \\
\hline \multirow[t]{2}{*}{ Gender, n (\%) } & Male & $30(93.8)$ & $46(83.6)$ & 1.87 & 0.17 \\
\hline & Female & $2(6.2)$ & $9(16.4)$ & & \\
\hline \multirow[t]{2}{*}{ Diagnosis, n (\%) } & Schizophrenia & $25(78.1)$ & $38(69.1)$ & 0.83 & 0.36 \\
\hline & Other diagnosis & $7(21.9)$ & $17(30.9)$ & & \\
\hline \multirow[t]{2}{*}{ Family psychiatric illness, n (\%) } & Present & $6(18.8)$ & $13(23.6)$ & 0.28 & 0.59 \\
\hline & Absent & $26(81.2)$ & $42(76.4)$ & & \\
\hline
\end{tabular}

${ }^{*} \mathrm{p}<0.05$. EEG: electroencephalogram, SD: standard deviation, mths: months, wks: weeks

Table 3. Logistic regression analysis showing predictors of EEG abnormalities associated with clozapine

\begin{tabular}{|c|c|c|c|c|c|}
\hline \multirow{2}{*}{ Predictors ${ }^{\dagger}$} & \multirow{2}{*}{ Wald } & \multirow{2}{*}{$\mathrm{p}$} & \multirow{2}{*}{ Odds ratio } & \multicolumn{2}{|c|}{$95 \%$ confidence interval } \\
\hline & & & & Lower & Upper \\
\hline Constant & 3.56 & 0.059 & 8.09 & & \\
\hline Age & 2.48 & 0.115 & 0.97 & 0.93 & 1.01 \\
\hline Gender (Male vs. Female) & 1.66 & 0.198 & 0.34 & 0.06 & 1.77 \\
\hline Clozapine dose & 0.68 & 0.408 & 1.00 & 0.99 & 1.01 \\
\hline Duration on clozapine & 0.05 & 0.818 & 0.99 & 0.89 & 1.09 \\
\hline $\begin{array}{l}\text { Medication status (clozapine only vs clozapine } \\
\text { with other medications) }\end{array}$ & 0.51 & 0.672 & 1.24 & 0.46 & 3.37 \\
\hline
\end{tabular}

${ }^{*} \mathrm{p}<0.05,{ }^{\dagger}$ predictors from step 1 of backward conditional method. EEG: electroencephalogram

\section{DISCUSSION}

The overall frequency of EEG abnormality was high (63.2\%) in our study, that is consistent with the existing literature. EEG abnormalities occurred in $66.7 \%$ of patients receiving more than clozapine $300 \mathrm{mg} /$ day; similar rates (72\%) were reported earlier. ${ }^{14}$ Treves and Neufeld ${ }^{24}$ had found EEG abnormalities in $64 \%$ of patients under clozapine at $300 \mathrm{mg}$ /day. Slowing of EEG in theta and delta range has been more frequent as compared to epileptiform activities in most studies, ${ }^{19}$ whereas, in our study both were equally prevalent (-40\%).

In their retrospective review, Gunther et al. ${ }^{17}$ found a dose dependent relationship between clozapine dose and EEG slowing, with $92 \%$ of 283 patients receiving more than $600 \mathrm{mg}$ clozapine exhibiting diffuse slowing. Liukkonen et al. ${ }^{25}$ reported background disturbance in 11, paroxysmal slow wave activity in 8, and epileptiform discharges in 4 out of 12 patients; patients with epileptiform discharges were on clozapine 300$700 \mathrm{mg}$ daily. In our study no such association was found. Nevertheless, moderate to severe abnormalities were more frequent in our study. Interestingly, EEG abnormalities were present in more than $50 \%$ patients, even in those receiving lower doses of clozapine (less than 100, 50 or $25 \mathrm{mg}$ per day). This finding underscores the importance of EEG monitoring in patients on lower doses of clozapine. However, these EEG abnormalities are not specific and the epileptiform activity is not necessarily associated with seizures, as observed in our study.

Quantitative EEG studies have reported an increase in theta and delta power and coherence changes in theta band following clozapine treatment. ${ }^{26}$ In that study, changes of coherence were correlated with changes on the Brief Psychiatric Rating Scale score, thus to clinical improvement. In a case study, sharp-slow wave activity was found bilaterally over frontal regions, and further source analysis localized these to the deep medial frontal region. ${ }^{27}$ Further studies are required to characterize these EEG changes prospectively.

The mechanism of clozapine-induced seizure is not known, although its effect on gamma-aminobutyric acid $\mathrm{A}\left(\mathrm{GABA}_{\mathrm{A}}\right)$ receptors ${ }^{28}$ has been implicated. The other possible mechanisms include its action on nicotinic acetylcholine receptors, ${ }^{29}$ glutamate N-methyl-D-aspartate (NMDA) receptors, ${ }^{3} 0$ serotonin $5-\mathrm{HT}_{2 \mathrm{~A}}{ }^{31}$ and strychnine-sensitive glycine receptors 33 that merits further evaluation. In a mouse model, expression of immediate early gene such as c-fos has been found in num- 
ber of subcortical sites and in orbital cortex of clozapine kindled myoclonic jerks. ${ }^{33}$

Recently it has been suggested that EEG findings should not be excessively relied upon as there is no consensus on using EEG data as a guide for optimal dosing of clozapine. ${ }^{34} \mathrm{Se}$ veral studies ${ }^{35,36}$ including ours, show that EEG abnormalities may be present without any association with clinical seizures, in contrast to the study by Welch et al. ${ }^{18}$ which suggested that the EEG is a sensitive indicator of clozapine toxicity and that changes such as the development of spikes and sharp waves indicate a high risk of convulsions. Larger studies are required to clarify this issue further.

In our cohort of 87 patients, EEG changes during clozapine therapy were common. Epileptiform activity was found in more than $40 \%$ of the patients and was of moderate to severe degree. However, in absence of baseline EEG, the issue of new onset abnormalities could not be clarified. Other limitation in our study includes heterogeneity of psychiatric diagnosis, the effect of which could not be examined due to small sample size. Also, serum clozapine levels were not measured in our study. It has been found that there are significant interand intra-individual variations in clozapine serum levels, for a given dose, and it has been attributed to its complex metabolism. ${ }^{21,37}$ A recent review ${ }^{38}$ found that although there was evidence for strong relationship between clozapine dose and plasma level and occurrence of clozapine-induced EEG abnormalities, there was no statistically significant relationship between dose and occurrence of seizures. The authors concluded that there is insufficient data to suggest direct relationship of clozapine plasma level with occurrence of seizures, though they found three case reports suggesting very substantial risk of seizures with clozapine plasma levels exceeding $1,300 \mu \mathrm{g} / \mathrm{L} \cdot{ }^{38}$ Nevertheless, therapeutic drug monitoring of clozapine has been suggested to be useful to identify signs of toxicity and onset of seizures. ${ }^{37}$

It is also interesting to note that in Asian patients, the plasma clozapine levels were higher with a given dose of clozapine, compared to Caucasian patients, and the findings remained significant even after controlling for gender, body mass index, cigarette, alcohol and caffeine use. ${ }^{39}$ Although ethnic differences in EEG abnormalities and seizures associated with clozapine has not been adequately studied, such variations might account for the differences in rates of EEG abnormalities. Two case studies ${ }^{40,41}$ described seizures occurring at lower clozapine doses in Asian patients, with very high serum levels in one report. In our study, frequent EEG abnormalities in those receiving lower doses of clozapine could reflect such ethnic variation, though such association is presumptive at best in the absence of plasma levels.

EEG abnormalities have also been reported to occur with ty- pical as well as other atypical antipsychotics. One study ${ }^{42}$ compared EEG abnormalities in those receiving antipsychotics $(\mathrm{n}=81)$ with normal healthy controls $(\mathrm{n}=30)$. Abnormal EEG was higher in those receiving olanzapine (35\%) and haloperidol $(23 \%)$ and was statistically significantly increased with dose in the olanzapine group, in contrast to patients treated with haloperidol, quetiapine or healthy subjects. Also, epileptiform activity was observed only in patients receiving olanzapine (11\%). In another study43 on a larger sample $(\mathrm{n}=323)$, EEG abnormalities were most frequent with clozapine (47\%), followed by olanzapine (38\%), risperidone (28\%), typical antipsychotics (14\%) and none with quetiapine. In that study, comorbid disorders and older age were associated with higher risk, whereas there was no relationship with dose or clinical response.

There is some evidence to suggest a favorable clinical response in specific groups of patients (females, major depressive disorder) predicted by EEG abnormalities before clozapine treatment. ${ }^{44}$ In another study, ${ }^{45}$ pretreatment intrahemispheric asymmetry on EEG predicted short-term response to clozapine treatment in schizophrenia. Also, EEG abnormalities developing after clozapine treatment appeared to be associated with good response in another small study. ${ }^{46}$

There is no consensus regarding antiepileptic prophylaxis in patients on clozapine without clinical seizures; some reports ${ }^{38}$ advising use of these medications at a certain clozapine dose or plasma level $(>500 \mu \mathrm{g} / \mathrm{L})$ or appearance of clear epileptiform discharges on EEG. However, as shown in our report, seizures were absent in patients receiving higher clozapine doses, even in the presence of epileptiform discharges on EEG. Therefore, routine use of anticonvulsants may not be warranted in patients having EEG abnormalities, even in those having epileptiform discharges. Nevertheless, it appears prudent to monitor for the clinical appearance of seizures in these patients, specifically with higher doses.

\section{REFERENCES}

1. Coward DM, Imperato A, Urwyler S, White TG. Biochemical and behavioural properties of clozapine. Psychopharmacology (Berl) 1989; 99(Suppl):S6-S12.

2. van Tol HH, Bunzow JR, Guan HC, Sunahara RK, Seeman P, Niznik $\mathrm{HB}$, et al. Cloning of the gene for a human dopamine D4 receptor with high affinity for the antipsychotic clozapine. Nature 1991;350:610-614.

3. Kane JM, Marder SR. Psychopharmacologic treatment of schizophrenia. Schizophr Bull 1993;19:287-302.

4. Tamminga CA, Thaker GK, Moran M, Kakigi T, Gao XM. Clozapine in tardive dyskinesia: observations from human and animal model studies. J Clin Psychiatry 1994;55 (Suppl B):102-106.

5. Alvir JM, Lieberman JA, Safferman AZ, Schwimmer JL, Schaaf JA. Clozapine-induced agranulocytosis. Incidence and risk factors in the United States. N Engl J Med 1993;329:162-167.

6. Devinsky O, Pacia SV. Seizures during clozapine therapy. J Clin Psychiatry 1994;55 (Suppl B):153-156 
7. Haller E, Binder RL. Clozapine and seizures. Am J Psychiatry 1990;147: 1069-1071.

8. Pacia SV, Devinsky O. Clozapine-related seizures: experience with 5,629 patients. Neurology 1994;44:2247-2249.

9. Devinsky O, Honigfeld G, Patin J. Clozapine-related seizures. Neurology 1991;41:369-371.

10. Wilson WH, Claussen AM. Seizures associated with clozapine treatment in a state hospital. J Clin Psychiatry 1994;55:184-188.

11. Michals ML, Crismon ML, Roberts S, Childs A. Clozapine response and adverse effects in nine brain-injured patients. J Clin Psychopharmacol 1993;13:198-203.

12. Baker RW, Conley RR. Seizures during clozapine therapy. Am J Psychiatry 1991;148:1265-1266.

13. Thomas P, Goudemand M. Seizure with low doses of clozapine. Am J Psychiatry 1992;149:138-139.

14. Isermann H, Haupt R. EEG-changes in paranoid-hallucinatory psychoses treated with Clozapine. Nervenarzt 1976;47:268.

15. Spatz R, Lorenzi E, Kugler J, Rüther E. The incidence of abnormal EEG patterns with clozapine therapy. Arzneimittelforschung 1978;28:14991500 .

16. Naber D, Holzbach R, Perro C, Hippius H. Clinical management of clozapine patients in relation to efficacy and side effects. Br J Psychiatry Suppl 1992;17:54-59.

17. Gunther W, Baghai T, Naber D, Spatz R, Hippius H. EEG alterations and seizures during treatment with clozapine. A retrospective study of $283 \mathrm{pa}-$ tients. Pharmacopsychiatry 1993;26:69-74.

18. Welch J, Manschreck T, Redmond D. Clozapine-induced seizures and EEG changes. J Neuropsychiatry Clin Neurosci 1994;6:250-256.

19. Malow BA, Reese KB, Sato S, Bogard PJ, Malhotra AK, Su TP, et al. Spectrum of EEG abnormalities during clozapine treatment. Electroencephalogr Clin Neurophysiol 1994;91:205-211.

20. Braun-Scharm H, Martinius J. EEG changes and seizures with clozapine medication in schizophrenic adolescents. Z Kinder Jugendpsychiatr 1991;19:164-169.

21. Haring C, Neudorfer C, Schwitzer J, Hummer M, Saria A, Hinterhuber $\mathrm{H}$, et al. EEG alterations in patients treated with clozapine in relation to plasma levels. Psychopharmacology (Berl) 1994;114:97-100.

22. Freudenreich O, Weiner RD, McEvoy JP. Clozapine-induced electroencephalogram changes as a function of clozapine serum levels. Biol Psychiatry 1997;42:132-137.

23. Volavka J, Abrams R, Taylor MA, Reker D. Hemispheric lateralization of fast EEG activity in schizophrenia and endogenous depression. Adv Biol Psychiatry 1981;6:72-75.

24. Treves IA, Neufeld MY. EEG abnormalities in clozapine-treated schizophrenic patients. Eur Neuropsychopharmacol 1996;6:93-94.

25. Liukkonen J, Koponen JH, Nousiainen U. Clinical picture and longterm course of epileptic seizures that occur during clozapine treatment. Psychiatry Res 1992;44:107-112.

26. Lacroix D, Chaput Y, Rodriguez JP, Filion M, Morrison D, St-Denis $P$, et al. Quantified EEG changes associated with a positive clinical response to clozapine in schizophrenia. Prog Neuropsychopharmacol Biol Psychiatry 1995;19:861-876.

27. Praharaj SK, Venkatesh BG, Sarkhel S, Zia-Ul-Haq M, Sinha VK. Clozapine-induced myoclonus: a case study and brief review. Prog Neuropsychopharmacol Biol Psychiatry 2010;34:242-243.
28. Squires RF, Saederup E. Clozapine and several other antipsychotic/antidepressant drugs preferentially block the same 'core' fraction of GABA(A) receptors. Neurochem Res 1998;23:1283-1290.

29. Singhal SK, Zhang L, Morales M, Oz M. Antipsychotic clozapine inhibits the function of alpha7-nicotinic acetylcholine receptors. Neuropharmacology 2007;52:387-394.

30. Arvanov VL, Wang RY. Clozapine, but not haloperidol, prevents the functional hyperactivity of $\mathrm{N}$-methyl-D-aspartate receptors in rat cortical neurons induced by subchronic administration of phencyclidine. J Pharmacol Exp Ther 1999;289:1000-1006.

31. Steward LJ, Kennedy MD, Morris BJ, Pratt JA. The atypical antipsychotic drug clozapine enhances chronic PCP-induced regulation of prefrontal cortex 5-HT2A receptors. Neuropharmacology 2004;47:527-537.

32. Liu Y, Hu C, Tang Y, Chen J, Dong M, Song T, et al. Clozapine inhibits strychnine-sensitive glycine receptors in rat hippocampal neurons. Brain Res 2009;1278:27-33.

33. Stevens JR, Denney D, Szot P. Kindling with clozapine: behavioral and molecular consequences. Epilepsy Res 1996;26:295-304.

34. Wong J, Delva N. Clozapine-induced seizures: recognition and treatment. Can J Psychiatry 2007;52:457-463.

35. Risby ED, Epstein CM, Jewart RD, Nguyen BV, Morgan WN, Risch SC, et al. Clozapine-induced EEG abnormalities and clinical response to clozapine. J Neuropsychiatry Clin Neurosci 1995;7:466-470.

36. Silvestri RC, Bromfield EB, Khoshbin S. Clozapine-induced seizures and EEG abnormalities in ambulatory psychiatric patients. Ann Pharmacother 1998;32:1147-1151.

37. Greenwood-Smith C, Lubman DI, Castle DJ. Serum clozapine levels: a review of their clinical utility. J Psychopharmacol 2003;17:234-238.

38. Varma S, Bishara D, Besag FMC, Taylor D. Clozapine-related EEG changes and seizures: dose and plasma-level relationships. Ther Adv Psychopharmacol 2011;1:47-66.

39. Ng CH, Chong SA, Lambert T, Fan A, Hackett LP, Mahendran R, et al. An inter-ethnic comparison study of clozapine dosage, clinical response and plasma levels. Int Clin Psychopharmacol 2005;20:163-168.

40. Lane HY, Su KP, Chang WH. Seizures after discontinuation of low-dose lorazepam from originally seizure-free clozapine regimen: combined effects? J Clin Psychiatry 1999;60:408-409.

41. Ravasia S, Dickson RA. Seizure on low-dose clozapine. Can J Psychiatry 1998;43: 420.

42. Amann BL, Pogarell O, Mergl R, Juckel G, Grunze H, Mulert C, et al. EEG abnormalities associated with antipsychotics: a comparison of quetiapine, olanzapine, haloperidol and healthy subjects. Hum Psychopharmacol 2003;18:641-646.

43. Centorrino F, Price BH, Tuttle M, Bahk WM, Hennen J, Albert MJ, et al. EEG abnormalities during treatment with typical and atypical antipsychotics. Am J Psychiatry 2002;159:109-115.

44. Pillay SS, Stoll AL, Weiss MK, Tohen M, Zarate CA Jr, Banov MD, et al. EEG abnormalities before clozapine therapy predict a good clinical response to clozapine. Ann Clin Psychiatry 1996;8:1-5.

45. Knott V, Labelle A, Jones B, Mahoney C. EEG hemispheric asymmetry as a predictor and correlate of short-term response to clozapine treatment in schizophrenia. Clin Electroencephalogr 2000;31:145-152.

46. Risby ED, Epstein CM, Jewart RD, Nguyen BV, Morgan WN, Risch SC, et al. Clozapine-induced EEG abnormalities and clinical response to clozapine. J Neuropsychiatry Clin Neurosci 1995;7:466-470. 